\title{
Monitoring streets through tweets: \\ Using user-generated geographic information to predict gentrification and displacement
}

Forthcoming in Environment and Planning B: Urban Analytics and City Science

Karen Chapple (University of California, Berkeley), Ate Poorthuis (KU Leuven), Matthew Zook (University of Kentucky), and Eva Phillips (University of California, Berkeley)

Corresponding author: Karen Chapple, chapple@ berkeley.edu

Acknowledgments: The authors would like to thank Catherine Bui and Kush Khanolkar for research assistance, and the anonymous referees for their insightful comments.

\begin{abstract}
The new availability of big data sources provides an opportunity to revisit our ability to predict neighborhood change. This article explores how data on urban activity patterns, specifically, geotagged tweets, improve the understanding of one type of neighborhood change gentrification -- by identifying dynamic connections between neighborhoods and across scales. We first develop a typology of neighborhood change and risk of gentrification from 1990 to 2015 for the San Francisco Bay Area based on conventional demographic data from the Census. Then, we use multivariate regression to analyze geotagged tweets from 2012 to 2015, finding that outsiders are significantly more likely to visit neighborhoods currently undergoing gentrification. Using the factors that best predict gentrification, we identify a subset of neighborhoods that twitter-based activity suggests are at risk for gentrification over the short term - but are not identified by analysis with traditional census data. The findings suggest that combining Census and social media data can provide new insights on gentrification such as augmenting our ability to identify that processes of change are underway. This blended approach, using Census and big data, can help policymakers implement and target policies that preserve housing affordability and protect tenants more effectively.
\end{abstract}

Keywords: gentrification, social media, big data, Twitter, neighborhood change 


\section{Introduction}

Beginning with the Chicago School, generations of urban theorists have studied neighborhood change, whether focused on segregation, gentrification, urban sprawl, or other processes (for example, see Jargowsky, 1997; Lees et al., 2016; Massey and Denton, 1993; Park, 1925). For many decades, studies have either relied primarily on demographic (census) data aggregated at the neighborhood level which mask complex and micro-scale causal dynamics, or utilized indepth case studies that limit generalization. While new methodological approaches for analysis have been developed (Delmelle, 2015), there remains ample opportunity for innovation. This is particularly the case for attempts to predict future change, particularly gentrification, as efforts to project change based on previous patterns have fallen surprisingly short (Chapple and Zuk, 2016).

The availability of powerful computational approaches and new data sources provides an opportunity to revisit traditional analyses of neighborhood change and increase predictive power. For instance, researchers have used machine learning techniques on existing census data records to analyze existing patterns of neighborhood ascent and decline in order to predict gentrification (Reades et al., 2019). Researchers have also used user-generated data on activity patterns, such as social media data, to refine traditional conceptions of residential segregation or predict housing price changes (Shelton et al., 2015; Steentoft et al., 2018). These types of data are particularly useful since they are available in "real-time" rather than on the periodic schedule of a census. Relatedly, data from other non-Census sources allow for insightful analysis on neighborhood change resulting from new practices such as short-term rentals (Wachsmuth and Weisler, 2018).

Following this vein, this paper explores how data on urban activity patterns, specifically, geotagged tweets, improve the understanding of one type of neighborhood changegentrification -- by identifying dynamic connections between neighborhoods. For this paper, we first develop a typology of neighborhood change from 1990 to 2015 for the San Francisco Bay Area, based on conventional demographic data, and identify non-gentrified areas vulnerable to gentrification, based on risk factors from previous decades. However, this risk category is too broad, both temporally and spatially, to be useful for policymakers seeking to target interventions. In order to narrow this category, we use a blended approach that combines Census data with a new big data source. More specifically, we validate the typology and refine the identification of at-risk areas with more recent data, by analyzing geotagged tweets from 2012 to 2015, to measure the extent to which outsiders (users not living in the tract from which they tweeted) spend time in different types of neighborhoods (see Shelton et al., 2015). Controlling for neighborhood and built environment variables, we identify the factors associated with outsider tweeting during visits and find that outsiders are significantly more likely to visit neighborhoods currently undergoing gentrification. We then determine the factors that best predict recent ongoing gentrification, finding that tweets from outsiders, among other 
factors, are statistically significant. Using these factors we identify a subset of neighborhoods that twitter-based activity suggests are at risk for gentrification over the short term - but are not identified by analysis with traditional census data. We conclude by discussing the policy implications and implementation possibilities. Combining census data with crowd-sourced big data for urban analysis remains relatively new (see Törnberg and Chiappini, 2020), and blended gentrification studies typically focus on the urban core rather than entire metropolitan regions (Gibbons et al., 2018; Hristova et al., 2016); thus a key aspect of this paper is understanding how blended data approaches can provide new insights on gentrification as it unfolds over decades across different types of neighborhoods.

\section{Empirical understandings of gentrification: From conventional to big data}

Considerable disagreement remains about how to operationalize neighborhood change, particularly gentrification. Most agree that gentrification is a form of neighborhood transformation that involves ascent rather than decline. However, some emphasize flows of capital over people and see gentrification as primarily about disinvestment and devaluation processes that then create a "rent gap" and thus new capital accumulation (Smith, 1979). Others pay more attention to the flows of people and analyze population shifts due to the transformation of production and/or consumption (Ley, 1996; Zukin, 1982). A similar debate has arisen about commercial or cultural gentrification and whether it arises from shifts in cultural consumption or forces of capital accumulation (Hackworth and Rekers, 2005). Yet there is relative consensus that it manifests in retail upscaling that attracts a new class and type of consumer to traditional commercial streets, in a visible and sudden transformation (Zukin et al., 2009).

Researchers often focus on low-income neighborhoods (generally operationalized as census tracts), as these areas are seen as particularly vulnerable to the influx of capital or population (see, for instance, Ding et al., 2016; Ellen and O'Regan, 2011; Freeman, 2005). The global gentrification literature expands gentrification to a wide variety of contexts, actors, and processes, in general de-emphasizing the role of individual consumption (Lees et al., 2016). Studies of U.S. housing markets place particular importance on understanding flows of people rather than capital, making displacement, or forced moves that occur despite having met legal conditions of occupancy, a key focus.

Gentrification-induced displacement may be direct, as landlords evict tenants, or indirect, caused by increasing rents. It may also be exclusionary, taking place when a household is simply unable to move into a neighborhood, typically because of housing costs (Marcuse, 1986). Researchers rarely study displacement via census data, given lack of data about mobility and choice. For instance, in the face of rent increases, some residents must leave, but others choose to stay and pay more rent. Given these challenges, most researchers tend to use simple mobility rates as a proxy for displacement (Ding et al., 2016; Ellen and O'Regan, 2011). 
Despite these issues, several studies attempt to create either typologies of gentrification and displacement risk, or stage measures of gentrification, for cities and/or regions using publicly available census data (Atkinson et al., 2011; Bates, 2013; Gibbons et al., 2018a; Regional Plan Association, 2017). ${ }^{1}$ Most of these approaches avoid statistical analysis, and none measure displacement empirically, i.e., the number of people leaving a neighborhood. Instead, they assume that hot housing markets result in displacement. Researchers have generally not bothered to validate their own predictions; one study that did found that it had a $79 \%$ false positive rate in predicting gentrification (Chapple and Zuk, 2016).

In this article, we begin by essentially replicating previous approaches, but we use regression to identify risk while also describing a variety of trajectories of neighborhood change in diverse areas throughout the region over an extended (twenty-five year) time period. Given that neighborhood change processes take time to unfold (Chapple and Loukaitou-Sideris, 2019), there is theoretical foundation for using this time-span. However, this fails to capture more rapid or recent changes, including reversals of neighborhood fortune or catalytic changes due to new development.

To counter this temporal disadvantage, this paper turns to a different data source, geolocated social media. User-generated geographic information offers the potential not only to provide more current - even real-time - data, but also allows researchers to pinpoint activity patterns at finer geographies than census tracts, which are not always aligned with 'real' neighborhood boundaries (Shelton and Poorthuis, 2019). Moreover, because much of this data is available at a relatively precise 'point' scale, researchers can create areal units that match local understandings and specificities. By using data generated by twitter users, rather than relying on measures of housing prices and tract-level demographics, researchers can also broaden the investigation of neighborhood change to the entire city, rather than just residential areas.

Prior research on neighborhood change using social media data has generally taken one of three tracks. First are studies that analyze perceptions of neighborhood change via social media content such as Zukin et al.'s (2017) analysis of Yelp reviews documenting "discursive redlining" in positive reviews for White-gentrifying neighborhoods, or Boy and Uitermark's (2017) study that shows that Instagram users elevate marquee locations and make others essentially invisible. Second is work that links spatial patterns such as gentrification to social network interactions, typically via blending census and social media data (Ye and Liu, 2018). This includes documenting the connection between check-ins from networks of affluent visitors in deprived neighborhoods and their subsequent economic improvement (Hristova et al., 2016), and the association of gentrifying neighborhoods with interactions among social media users (Gibbons et al., 2018b). These latter two studies also connect neighborhood change explicitly to

\footnotetext{
${ }^{1}$ Notably, other gentrification researchers have augmented Census data with data from other sources - such changes to the built environment (Wyly and Hammel, 1998) and mortgage borrowing (Wyly and Hammel 1999).
} 
the rise of popular restaurants, bars, and cafes. Third are projects that use tweets to track activity patterns with a focus on the relationship to housing price changes. Just examining activity spaces of different socio-economic groups via geotagged tweets can develop new conceptions of how neighborhoods are produced (Shelton et al., 2015) and even yield early predictions of rent increases (Steentoft et al., 2018). This paper builds upon and connects elements of the second and third tracks, by tracking the mobility of social media users and using this to create a network between places. This allows us to identify the socio-economic characteristics of outsiders to gentrifying neighborhoods and consider how this new information can help identify areas at risk of change.

To be clear, however, the use of user-generated data does come with both technical and ethical problems. For example, relying on Twitter for its time-stamped geotags has its shortcomings, raising questions of internal validity (Offenhuber, 2017) and creating problems for interpretation. Local context often shapes the choice whether to post on social media, rendering some places or times more likely to be documented than others (Boy and Uitermark, 2017). As a result, the distribution of Twitter activity cannot be assumed to be representative as uneven access, inhospitable contexts, or multiple other factors intervene. Therefore, throughout this paper we make no claim or use of Twitter data as a representative sample of the population. Instead, we argue that analyzing changes in the spatial footprints of the Twitter platform provides insight to a subset of gentrification processes that augment an understanding based solely on census data. In short, Twitter data does not allow us to make claims on the general prevalence of gentrification (as we can with Census data). It does provide us with evidence that gentrification-related activity (dynamic connections between places within an urban region) exists, which is why combining Census and big data is potentially useful.

Relatedly, great care should be taken in interpretation of the meaning of any social media posting (Poorthuis et al., 2020). For this reason, this paper treats a tweet simply as an indicator of presence rather than ascribing deeper meaning. Ethical concerns are important to consider as gathering larger amounts of social media data allows researchers to build detailed profiles on individual movement and speech (Zook et al., 2017). For this reason, all data presented in this paper is shown at aggregate levels without identifying details. Finally, we recognize that online activity can have a direct effect on how material places function (Zook and Graham, 2007) and can contribute to creating and expanding social divides. However, establishing such a causal connection is challenging and would require a different approach (see Spangler, 2020; Törnberg and Chiappini, 2020) that is tangential to this paper's primary goal of examining how blending census and big data sources can provide new insights on the gentrification process.

\section{Data and methods}

This paper requires multiple steps of data preparation. First, we create a standard typology of gentrification using Census data to categorize neighborhoods by stage of gentrification, 
displacement, and exclusion, generally following methodologies put forth by Bates (2013) and the Urban Displacement Project (Thomas et al., 2020), and definitions of gentrification that include both influxes of new residents and capital, following Freeman (2005) and Ding et al. (2016). Then, to address some of the shortcomings of this conventional approach, most specifically the temporal lag that prevents identifying more recent changes, we examine mobility between neighborhoods as measured by Twitter users.

While we could conduct this analysis for any large metropolitan area, we chose the case of the San Francisco Bay Area megaregion given the prevalence of and rapid change in gentrification throughout the region (Chapple and Zuk, 2016). For the last fifty years, the success (and occasional failures) of the information technology sector has shaped the story of this region: innovative firms have attracted high-skilled young in-migrants, who drive up housing prices in the core and force lower-wage workers into long commutes from throughout the megaregion (Storper et al., 2015). From 2000 to 2015, housing prices in the core of the region doubled, compared to a 75 percent increase overall in twenty major metropolitan areas in the United States (S\&P, 2021). The megaregion includes the five core counties that comprise the metropolitan areas of San Francisco, San Jose, and Oakland (San Francisco, San Mateo, Santa Clara, Alameda, and Contra Costa); the remaining four counties considered part of the commuter shed (Marin, Sonoma, Solano, and Napa); plus Santa Cruz, Sacramento, Yolo, and San Joaquin counties. These counties range in density from urban (18,562 persons per square mile in San Francisco) to largely rural (e.g., 162 persons per square mile in Solano County). Thus, although core areas of the region may be considered an extreme case study in terms of gentrification, the entire study area represents a diversity of urban forms and housing submarkets (Yin, 2017).

\section{Creating a typology of neighborhood change}

In order to designate neighborhoods by their stage of change we use data from the Decennial Census (1990, 2000) and American Community Survey (2011-2015). To reconcile the changes in tract boundaries from earlier time periods, we used Brown University's Longitudinal Tract Data Base (LTDB), which normalizes census tract data from each year to 2010 census tract boundaries to maximize comparability across the study period. In the case of variables not provided by the LTDB, we downloaded the original raw data and used LTDB's crosswalk.

We characterize change in both low- and high-income neighborhoods, looking at gentrification and displacement in the former and exclusion in the latter. We thus divide the region into lowincome neighborhoods at $80 \%$ of area (county) median household income or less, and moderate- to high-income neighborhoods with median income above $80 \%$ of area (county) median household income. We select these thresholds to be consistent with affordable housing policies and programs. (Table S1 presents the full typology methodology.) 
To describe the neighborhoods where gentrification and displacement are taking place, most studies first pinpoint the neighborhoods with potential to change (or the "eligible" tracts) (Chapple and Zuk, 2016; Ding et al., 2016; Freeman, 2005; Gibbons et al., 2018b). To do this, we use several different indicators. Vulnerability to change is defined by availability of affordable housing, so we select neighborhoods where either rents or housing values are below the area (county) median. We also select areas with low college education, and high low-income households, renters, and nonwhite households, all relative to the median. "Eligible" neighborhoods must have housing affordability plus any two of the four demographic characteristics.

We characterize neighborhood change in the form of gentrification (operationalized as the influx of investment and people into low-income areas); displacement (the loss of low-income households without replacement, in low-income areas) and exclusion (when displacement is occurring in high-income neighborhoods). We measure gentrification via the change in real median housing value or rent above the county median change, as well as growth in share of college educated population and household median income greater than the median change; we also include a measure of exclusionary displacement, i.e., decrease in the in-migration rate of low-income households. To measure displacement and exclusion, we use two indicators absolute loss of low-income households between census years and decrease in in-migration.

We rely on logit regression to identify the key long-term predictors of ongoing gentrification in eligible (vulnerable) tracts, analyzing the entire twenty-five year period from 1990 to 2015 (Table 1). For gentrification, the significant factors include high shares of historic housing (built pre-1950) and recent new housing construction; a central city location; and lack of local housing and employment density, as well as households with children. ${ }^{2}$ These are the factors typically identified by the literature, with the exception of the density variables. This unintuitive finding likely results from the diverse urbanization patterns in the thirteen counties under study: for example, high density tracts may either have very little housing or be dominated by high-end apartment buildings with little opportunity for gentrification, while rural towns may have gentrifying cores surrounded by low employment and population density. We categorize neighborhoods that score above the regional median (or below, for the negative factors) on at least half the significant factors as at risk.

[Table 1. Factors predicting ongoing gentrification, 1990-2015.]

Figure 1 maps the results of this classification, both identifying historic change and predicting areas likely to change in the future. Overall, of the 2,138 census tracts, $5 \%$ have already gentrified, $10 \%$ are currently undergoing gentrification, $3.5 \%$ are currently undergoing

\footnotetext{
${ }^{2}$ Household income, income squared and renter are also significant, but are measured in the dependent variable and thus endogenous, so we do not consider them risk factors.
} 
displacement without gentrification, $31 \%$ are in some stage of exclusion, and $11 \%$ are at risk of gentrification (see Table S1). The remaining $39 \%$ of tracts are classified as stable.

[Figure 1 Typology of gentrification and displacement in the San Francisco Bay Area]

While not discounting the work required to produce this typology or its usefulness, one potential critique is that it identifies a relatively large number of "at-risk" neighborhoods (or census tracts), 241 in total. Given limited resources for policy making, an important question is how this prediction might be refined, particularly controlling for more recent activity than available from the census. For this, we now turn to the second stage of the analysis to use geotagged Twitter data to investigate how it helps distinguish neighborhood types and identify areas where change is imminent.

\section{Preparing Twitter data}

We began our analysis with a dataset of geotagged tweets ( 54.5 million in total) for the 13 counties of the San Francisco Bay Area megaregion sent between July 2012 and June 2015, collected by the DOLLY archive at the University of Kentucky. In order to link this data to our gentrification typology we followed five steps: determining home and adjacent location, eliminating 'power' users, identifying characteristics of the home tract, and adding new control variables.

Identifying home and adjacent location. To determine the home location for users we first removed all users with less than 20 tweets in our dataset to ensure a sufficient number of observations. The remaining 51.8 million geotagged tweets were sent by 183,715 users. For these, we use a relatively simple filtering algorithm to determine the most likely home location, or more specifically the location where users had a sustained presence. A home location (defined as a census tract) needs to be the location of at least 10 tweets, sent on at least 7 different days and during 8 or more different hours of the day. If multiple locations satisfy, we use the location with the most tweets. With this method, we are able to assign a home location for 102,338 users who sent a total of 47.65 million tweets within a census tract location. ${ }^{3}$ This represents only $13.5 \%$ of all users, and $55.7 \%$ of those users who sent more than 20 tweets during the study period. Although different values could be chosen for the parameters used in the inference of the most likely home location, we opt for a relatively conservative approach to prevent assigning users to a location that neither is their home nor plays any role as a 'base' location in their life. In this sense, we have designed this procedure to prevent false positives

\footnotetext{
${ }^{3}$ Of the 2250 total census tracts, only 314 slightly underrepresented tweets with home location (less than $0.03 \%$ missing) relative to all tweets. Thus, the tracts with home location are a good overall representation of the population of geotagged tweets. To eliminate noise from tourists, we dropped all tweets with a home tract outside the megaregion.
} 
(cf. Chen and Poorthuis, 2021 for a sensitivity analysis and discussion of different home location algorithms).

Using nearest neighbor analysis in ArcGIS we identify tracts adjacent to the home tract, herein called "neighbor" tracts. From this we categorize all remaining tweets by user-type: local, neighbor or non-local (outsider). These categories of user-type, relative to the census tract, are defined as follows:

- Local: User's home location is within the census tract.

- Neighbor: User's home location is adjacent to the census tract.

- Non-local (outsider): User's home location is neither in nor adjacent to the census tract.

The neighbor category allows us to differentiate between local and non-local outsiders and address boundary issues: for instance, tweets that emanate from opposite sides of the street, from two different census tracts, might otherwise be categorized as home and outsider, but are both essentially local. Figure 2 illustrates the three tweet types in the City of San Francisco, using only a one percent sample of the tweets for visual clarity. The figure validates our approach by suggesting a concentration of outsider tweets not only in the downtown central business district, but along the city's major arterials. We acknowledge the imprecision of the "outsider" definition, i.e., outsiders are not necessarily indicative of gentrification and could represent people going to work or visiting family and friends. Nevertheless, the value in its use is that it captures a dynamic that is absent from the residential census (movement between places). Despite potential imperfections in this operationalization, exploring what new insights may be gained is a worthwhile endeavor. Moreover, in our regression models, we control for commercial land use in an attempt to account for the possibility that this indicator is capturing work locations.

[Figure 2. Geotagged tweets in the City of San Francisco, 2012-2015 (one percent sample).]

Eliminating Power users. It is also important to control for extremely active users, or powerusers, so that the activity of a single twitter account does not unduly shape the results by tweeting repeatedly from the same location. To do this we filter the data to include only one tweet per user per day per tract, which still gives frequent visitors relative importance in the dataset, and leaves 14,585,347 tweets and 102,338 users in the dataset. ${ }^{4}$

Identifying characteristics of the home tract. Given our ultimate goal of understanding the nature of visitors to gentrifying neighborhoods we need to assign users demographic characteristics. We do this by associating users (and their tweets) the characteristics, including

\footnotetext{
${ }^{4}$ Another approach might have been to weight the users by number of tweets. We instead limited to one tweet per user per day in order to account for repeat visits. In other words, we are not just interested in measuring the diversity of users, but whether users visited repeatedly.
} 
income, race/ethnicity, and education, of their home census tract according to the 2011-2015 American Community Survey. Income is defined relative to the county median household income: over 120 percent and under 80 percent of county median qualified as high-income and low-income respectively, and the remaining as middle-income. User with home tracts with concentrations of racial/ethnic groups over the county median are characterized as dominant Latinx, non-Hispanic Black, or Asian. Likewise, we define users as coming from college-educated tracts if the percentage of college-educated residents in their home tract is greater than the county median. Because of the potential ecological fallacy that results from this approach, we use these socio-economic characteristics not in the models but in exploratory descriptive statistics.

Other characteristics. To characterize the built environment where tweeting takes place, we use variables measuring central city location (San Jose, San Francisco, or Oakland); transit neighborhood (location in a census tract that intersects the $1 / 2$-mile radius of a fixed rail transit station); percent of tract parcels in commercial land use (calculated using county tax assessor data); employment density (calculated using the Longitudinal Employer-Household Dynamics data); population density (calculated from the American Community Survey); and housing age (calculated from the American Community Survey). These variables proxy for the elements of centrality, accessibility and architectural quality described as driving gentrification in the literature, as well as the connection between commercial uses, social media use, and neighborhood change (Gibbons et al., 2018b; Hristova et al., 2016).

We begin the analysis by describing the characteristics of users (based on their home tracts) tweeting in different neighborhoods and link this to our typology of gentrification and displacement. Next, we examine how outsider tweets improve our gentrification prediction model in Table 1. Then, we use OLS regression to identify the factors behind outsider tweets in a particular neighborhood, with a close look at how neighborhood types predict visits from these outsiders. After establishing the relationship between outsiders and neighborhoods undergoing gentrification, we conclude by using tweeting patterns to help refine the identification of neighborhoods at risk for gentrification.

\section{Analyzing tweeting by neighborhood and user type}

To determine tweet patterns by neighborhood, we examine how tweeting by the three types of users - local, neighbor, and outsider - varies across neighborhoods defined by socio-economic and built environment characteristics. The average tract had 2,409 geotagged tweets from local users, 810 tweets from users in neighboring tracts, and 3,292 tweets from outsiders. In general, locals and neighbors tweet about the same amount regardless of neighborhood type, although users from tracts with above-median shares of African-American and Asian residents, as well as very high-income residents, are slightly more likely to tweet from their local tract (Table S2 provides location quotients based on average tweets by user type in each neighborhood type). 
Concentrations of outsider tweets occur across a variety of neighborhood types including those lacking: households with children, very-high income households, and Latinx residents. Outsider tweets are also concentrated in tracts with higher than median levels of older millennials (age 25-34), Asians, college-educated and very low-income residents. Tracts located in the central city or transit neighborhoods, with a high share of commercial parcels, high employment and population densities, and concentrations of both new and historic housing are also characterized by high location quotients for outsider tweets.

There is also a correlation between outsider tweets and gentrification, with very high concentrations in neighborhoods undergoing gentrification (LQ 1.81) or classified as experiencing advanced gentrification (LQ 1.32). While gentrifying neighborhoods also have high concentrations of local Twitter users, this is also observed in stable moderate to high-income neighborhoods albeit without the same level of outsider activity.

Given the concentration of outsider tweeting in gentrifying neighborhoods, it is important to understand where these outsiders are coming from. A disproportionate share comes from people associated with neighborhoods that are also either undergoing gentrification or in a state of advanced gentrification (Figure S1).

The distribution of outsider tweeting across the region is uneven not only in terms of neighborhood types but also according to the home tract demographics associated with users. Outside users from low-income tracts tweet disproportionately in the East Bay while users from middle-income tracts tweet in San Francisco and the South Bay (Figures S2 and S3). Users from tracts with higher education levels tend to tweet in the urban core and university campuses (Figures S4 and S5). Users from both African-American and Latinx neighborhoods tend to tweet in the East Bay (Figures S6 and S7). More generally speaking, neighborhoods with disproportionate outside tweeting tend either to be gentrifying or visitor locations, such as Golden Gate Park, airports, or downtowns.

Another lens into tweeting patterns comes from the timing of tweets. In neighborhoods with ongoing or advanced gentrification, there is a disproportionate share of outsiders tweeting across all time periods (Figure $\mathrm{S} 8$ ).

\section{Using outsider tweets to predict gentrification}

In this section, we shift to multivariate analysis to better understand the relationship between outsider tweeting and gentrification. The census data used to create the gentrification typology (1990, 2000, and 2011-15) mostly predates our Twitter dataset (2012-15), meaning that outsider tweeting may represent either a predictor of gentrification or an outcome of gentrification. To account for this, we model gentrification as both a dependent and an independent variable. More specifically, we examine associations with outsider tweeting during 
visits. Finally, we expand our original model of factors predicting gentrification over a 25 -year period to include outsider tweets.

What, then, is associated with disproportionate tweeting from outsiders in a neighborhood?. Using the independent variables used earlier in creating location quotients (see Table S2) we use OLS regression to predict the number of outsider tweets in each tract resulting in an adjusted $R^{2}$ of 0.28 and no issues of multi-collinearity or spatial autocorrelation (see Table 2). The regression identifies a number of socio-economic and built environment characteristics that predict outsider tweets. These include: a higher share of college-educated and millennial (25-34 year old) residents; a lower share of households with children predict outsider tweets; locations within the central city or a transit neighborhood; high shares of commercial parcels and historic housing; and low densities both in terms of employment and population. Most significantly for this project, neighborhoods categorized as low-income in which ongoing gentrification is taking place were also a significant predictor of outsider tweets, in fact the only neighborhood type that was significant. This suggests then that this type of neighborhood change is indeed distinct from others, including ongoing displacement, where residents are moving out but often in a context of disinvestment instead of gentrification.

\section{[Table 2. Predicting outsider tweets.]}

Shifting to using outsider tweets as an independent variable, Table 3 revisits the regression presented in Table 1, with the inclusion of outsider tweets. The effect of outsider tweets is significant, and its impact only trails that of share of renters and historic housing. Adding the variable improves the model slightly, most notably for gentrifying tracts, predicting $79.8 \%$ of the cases ( $54 \%$ of the gentrified cases) rather than $77.7 \%$ ( $48 \%$ of the gentrified).

[Table 3. Factors predicting ongoing gentrification 1990-2015, including outsider tweets.]

This association between visitors tweeting in a tract and gentrification suggests that outsider tweets could contribute to an early warning system for gentrification. In the next section, we explore what that could look like.

\section{Identifying tracts at risk}

The neighborhood change typology identified eight risk factors for gentrification and found that, based upon current characteristics, some 241 census tracts were at risk for change over the long-term. Using data on outsider tweets, we can identify which of these tracts are already experiencing heightened activity from outsiders. Of the at-risk tracts, 108 are currently experiencing an above-median share of outsider tweets. Figure 3 shows the number of traditional risk factors associated with each tract, and adds cross-hatching to identify which are also experiencing an above-median outsider twitter activity. Although areas throughout the 
region's cities and suburbs are at risk, the areas with disproportionately high incidence of outsider tweets tend to be either adjacent to gentrified areas (e.g., Oakland, San Leandro, south San Francisco, Sacramento), tourist areas (e.g., Point Reyes), or college towns (e.g., Santa Cruz). Outsider tweets are also correlated with several of the same risks identified in the neighborhood change typology, including low share of households with children, high share of historic housing, central city location, and high share of renters (see Table S3). However, some other risk factors are not correlated with this twitter activity, most notably a hot real estate market. This is consistent with the idea that outsider tweets may act as an early indicator of gentrification activity, before real estate activity has increased significantly.

[Figure 3. Tracts at risk for gentrification by risk factor and outsider tweets.]

In an effort to develop a more refined understanding of gentrification risk and its association with outsider tweets, we compare the characteristics of neighborhoods at risk to already gentrifying neighborhoods. If low-income at risk tracts share similar attributes with gentrifying areas (including the disproportionate presence of outsider tweets) they might be particularly susceptible. We explore this by conducting difference of proportions tests to examine the differences in a set of characteristics in at risk and gentrifying neighborhoods with below or above median share of outsider tweets. Tracts with ongoing gentrification share certain demographic characteristics (high shares of college-educated residents and 25-34 year-olds, low shares of Latinx residents), as well as certain built environment characteristics (walkability, transit accessibility, commercial land use, and density) (Table S4). Outside twitter users coming to these neighborhoods come disproportionately from high-educated, high-income, and nonLatinx neighborhoods.

Using this information, we might further refine our subset of 108 low-income neighborhoods at risk. For example, commercial neighborhoods near transit with a concentration of 25-34 yearolds within this group of 108 include Broadway Auto Row in Oakland and downtown Redwood City. Other neighborhoods that are highlighted via this exercise include Portola in San Francisco (a walkable, dense neighborhood with a relative low share of Latinx residents) and El Sobrante in Contra Costa County, a diverse community with low levels of college education and housing appreciation. Other neighborhoods like Bolinas (Marin County) are surprises given their existing concentrations of high-income, high-educated, non-Latinx users living alongside long-term lowincome residents, but do experience high levels of tourism that could put oldtimers at risk.

\section{Conclusion and Policy Implications}

Neighborhood change leads to windfall profits for some and displacement for others. Stakeholders from real estate speculators to policy makers seek the ability to predict how change will transpire. This research first analyzes the performance of conventional methods of analyzing potential risk of gentrification, and then shows how twitter data can not only improve 
prediction but also help pinpoint areas at risk even when real estate activity has not yet accelerated. This study augments previous studies pioneering blended approaches (such as Hristova et al. 2016 and Gibbons et al. 2018b) in several ways: identifying home locations of Twitter users, examining the socio-economic characteristics of visitors to gentrifying areas, blending Twitter data with a typology of neighborhood change, controlling for commercial land use, and adopting a study area that encompasses an entire, diverse megaregion.

The findings suggest that social media data, blended with census data, can serve as an early warning indicator that processes of change are underway. When outsiders tweet in a neighborhood, it is more likely to be undergoing gentrification, controlling for other factors such as commercial land use. The presence of tweets from outsiders in a low-income neighborhood that has not yet gentrified may suggest that the area is about to undergo change. Certain types of areas may be more susceptible, such as higher-density, more walkable commercial neighborhoods near transit. Tweets that are disproportionately from people who live in higher-income, higher-educated, less ethnically diverse neighborhoods may be an indication of change to come.

This study has certain limitations that future research can hopefully address. First, because we only had three years of geotagged tweets, we were not able to use this data to look at change over time, instead linking it to census data from different timeframes. Future studies should attempt to link time periods more precisely. Second, ascribing home neighborhood demographic characteristics to twitter users is an imperfect proxy given the diversity of neighborhood residents; still, to the extent that it is possible to identify user demographics more precisely, this could be a fertile area for further research. Third, these findings rely on just one form of social media data, Twitter; yet other forms with growing popularity, such as Instagram, may prove to be even more powerful in predicting neighborhood change. Fourth, areas undergoing (or about to undergo) gentrification are likely experiencing population turnover generally, so qualitative research might help to reveal exactly what mobility data is capturing. Finally, aggregating twitter data into districts creates statistical bias in the form of the modifiable areal unit problem, which methods such as applying a hexagonal grid can reduce (Openshaw, 1983).

Nonetheless, our findings have important implications for policymakers seeking to mitigate the negative impacts of gentrification, which can uproot longstanding communities. Models that try to predict gentrification often result in false positives, and incorporating new data sources should help produce more accurate predictions. Previous studies focus primarily on dense urban gentrifying areas, while our results encompass both rural and urban areas, which make them relevant across different jurisdictions. A better understanding of where change is about to occur will help policymakers implement and target policies that preserve housing affordability and protect tenants more effectively. Of course, private sector real estate interests are actively 
using big data to do the same (Stewart 2019), but tools like these can empower the public sector to keep pace. 


\section{References}

Atkinson R, Wulff M, Reynolds M, and Spinney A (2011) Gentrification and displacement: The household impacts of neighbourhood change. Report, Australian Housing and Urban Research Institute, Australia.

Bates L (2013) Gentrification and displacement study: Implementing n equitable inclusive development strategy in the context of gentrification. Report, Portland State University, Oregon.

Boy JD and Uitermark J (2017) Reassembling the city through Instagram. Transactions of the Institute of British Geographers 42(4): 612-624.

Chapple K and Loukaitou-Sideris A (2019) Transit-Oriented Displacement or Community

Dividends: Understanding the Effects of Smarter Growth on Communities. Cambridge, MA: MIT Press.

Chapple K and Zuk M (2016) Forewarned: The Use of Neighborhood Early Warning for Gentrification and Displacement. Cityscape 18(3): 109-130.

Chen $Q$ and Poorthuis A (2021) Identifying home locations in human mobility data: an opensource R package for comparison and reproducibility. International Journal of Geographical Information Science. In press.

Delmelle EC (2015) Five decades of neighborhood classifications and their transitions: A comparison of four US cities, 1970-2010. Applied Geography 57: 1-11.

Ding L, Hwang J, and Divringi E (2016) Gentrification and residential mobility in Philadelphia. Regional Science and Urban Economics 61:38-51.

Ellen IG and O'Regan KM (2011) How low income neighborhoods change: Entry, exit, and enhancement. Regional Science and Urban Economics 41(2): 89-97.

Freeman L (2005) Displacement or succession? Residential mobility in gentrifying neighborhoods. Urban Affairs Review 40(4): 463-491.

Gibbons J, Barton M, and Brault E (2018) Evaluating gentrification's relation to neighborhood and city health. PLOS ONE 13(11): e0207432.

Gibbons J, Nara A, and Appleyard B (2018) Exploring the imprint of social media networks on neighborhood community through the lens of gentrification. Environment and Planning $B$ : Urban Analytics and City Science 45(3): 470-488.

Hackworth J, and Rekers J (2005) Ethnic packaging and gentrification: The case of four neighborhoods in Toronto. Urban Affairs Review 41(2): 211-236.

Jargowsky PA (1997) Poverty and Place: Ghettos, Barrios, and the American City. New York: Russell Sage Foundation.

Lees L, Shin HB, and López-Morales E (2016) Planetary Gentrification. Hoboken, NJ: John Wiley 
and Sons.

Ley D (1996) The New Middle Class and the Remaking of the Central City. Oxford Geographical and Environmental Studies. Oxford: Oxford University Press.

Marcuse $P$ (1986) Abandonment, gentrification, and displacement: The linkages in New York City. In: Smith N and Williams P (eds) Gentrification of the City. London: Routledge, pp. 153177.

Massey DS and Denton NA (1993) American Apartheid: Segregation and the Making of the Underclass. Cambridge, Mass: Harvard University Press.

Offenhuber D (2017) Sticky data: context and friction in the use of urban data proxies. In: Kitchin R, Lauriault T, and McArdle G (eds) Data and the City. Abingdon, Oxon: Routledge, pp. 118-128.

Openshaw S (1983) The modifiable areal unit problem. Norwick: Geo Books.

Park RE (ed) 1925 The City: Suggestions of Investigation of Human Behavior in the Urban Environment. Chicago: University of Chicago Press.

Poorthuis A, Power D, and Zook M (2020). Attentional Social Media: Mapping the Spaces and Networks of the Fashion Industry. Annals of the American Association of Geographers 110(4): 941-966.

Reades J, De Souza J, and Hubbard P (2019) Understanding urban gentrification through machine learning: Predicting neighbourhood change in London. Urban Studies 56(5): 922942.

Regional Plan Association (2017) Pushed out: Housing displacement in an unaffordable region. Report, Regional Plan Association, New York.

S\&P Dow Jones Indices LLC (2021) S\&P/Case-Shiller 20-City Composite Home Price Index [SPCS20RSA]. Retrieved from FRED, Federal Reserve Bank of St. Louis, https://fred.stlouisfed.org/series/SPCS20RSA, March 9, 2021.

Shelton T and Poorthuis A (2019) The nature of neighborhoods: using big data to rethink the geographies of Atlanta's Neighborhood Planning Unit system. Annals of the American Association of Geographers (109)5: 1341-1361.

Shelton T, Poorthuis A, and Zook M (2015) Social media and the city: Rethinking urban sociospatial inequality using user-generated geographic information. Landscape and Urban Planning 142: 198-211.

Smith N (1979) Toward a theory of gentrification: A back to the city movement by capital, not people. Journal of the American Planning Association 45(4): 538-548.

Spangler, I. (2020). Hidden value in the platform's platform: Airbnb, displacement, and the unhoming spatialities of emotional labour. Transactions of the Institute of British Geographers, 45(3): 575-588. 
Steentoft A A, Poorthuis A, Lee B , and Schläpfer M (2018) The canary in the city: Indicator groups as predictors of local rent increases. EPJ Data Science 7(1): 7-21.

Stewart M (2019) The real estate sector is using algorithms to work out the best places to gentrify. Failed Architecture. https://failedarchitecture.com/the-extractive-growth-ofartificially-intelligent-real-estate/

Storper M, Kemeny T, Makarem N, and Osman T (2015) The rise and fall of urban economies: Lessons from San Francisco and Los Angeles. Palo Alto, CA: Stanford University Press.

Thomas T, Hartmann C, Driscoll A, Chapple K, Cash A, Elias RR, and Zuk M (2020) The Urban Displacement Replication Project: A Modified Gentrification and Displacement Methodology for the Atlanta, Chicago, Denver, and Memphis SPARCC Regions. Berkeley, California: Urban Displacement Project.

Törnberg P and Chiappini L (2020) Selling black places on Airbnb: Colonial discourse and the marketing of black communities in New York City'. Environment and Planning A: Economy and Space. 52(3), 553-572.

Wachsmuth D and Weisler A (2018) Airbnb and the rent gap: Gentrification through the sharing economy. Environment and Planning A: Economy and Space 50(6): 1147-1170.

Wyly EK and Hammel DJ (1998) Modeling the context and contingency of gentrification. Journal of Urban Affairs 20(3): 303-26.

Wyly EK and Hammel DJ (1999) Islands of decay in seas of renewal: Housing policy and the resurgence of gentrification. Housing Policy Debate 10(4): 711-71.

Ye X and Liu X (2018) Integrating social networks and spatial analyses of the built environment. Environment and Planning B: Urban Analytics and City Science 45(3): 395-399.

Yin RK (2017) Case Study Research and Applications: Design and Methods. Thousand Oaks, CA: Sage Publications.

Zook, M. A., \& Graham, M. (2007). The creative reconstruction of the Internet: Google and the privatization of cyberspace and DigiPlace. Geoforum, 38(6), 1322-1343.

Zook M, Barocas S, boyd d, Crawford K, Keller E, Gangadharan S P, Goodman A, Hollander R, Koenig B, Metcalf J, Narayanan A, Nelson A, and Pasquale F (2017). Ten Simple Rules for Responsible Big Data Research. PLOS Computational Biology. March 31.

https://doi.org/10.1371/journal.pcbi.1005399

Zukin S (1982) Loft Living: Culture and Capital in Urban Change. Baltimore: Johns Hopkins University Press.

Zukin S, Lindeman S, and Hurson L (2017) The omnivore's neighborhood? Online restaurant reviews, race, and gentrification. Journal of Consumer Culture 17(3): 459-479.

Zukin S, Trujillo V, Frase P, Jackson D, Recuber T, and Walker A (2009) New retail capital and neighborhood change: Boutiques and gentrification in New York City. City and Community 8(1): 47-64. 
Figure 1. Typology of gentrification and displacement in the San Francisco Bay Area

Gentrification and Displacement Typology

Lower income (LI) tracts

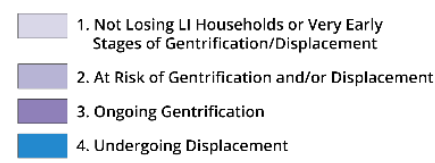

Moderate to high income $(\mathrm{MHI})$ tracts 1. Advanced Gentrification

2. Not losing LL Households or Very Early Stages of Displacement

3. At Risk of Exclusion

4. Ongoing Exclusion
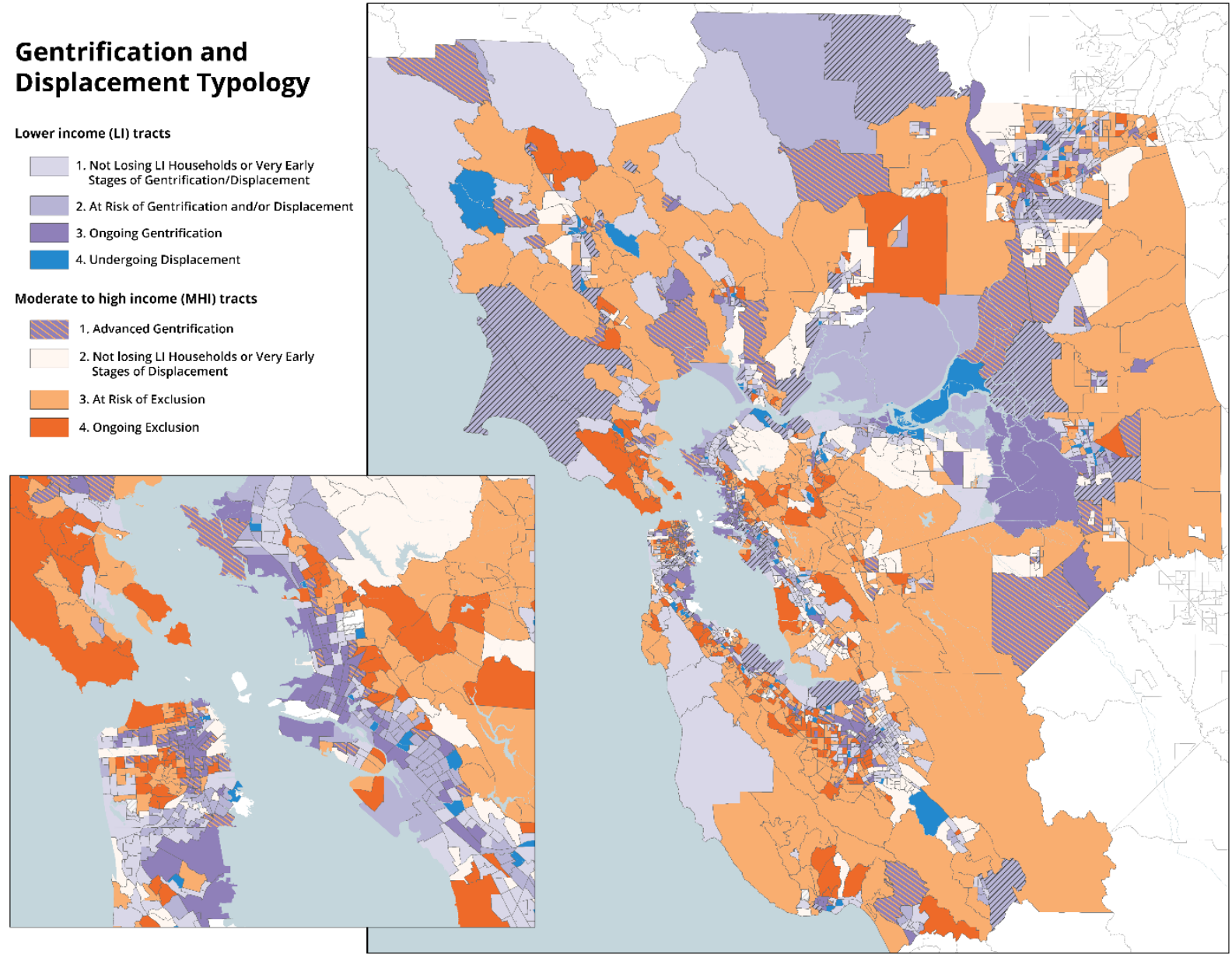
Figure 2. Geotagged tweets in the City of San Francisco, 2012-2015 (one percent sample).
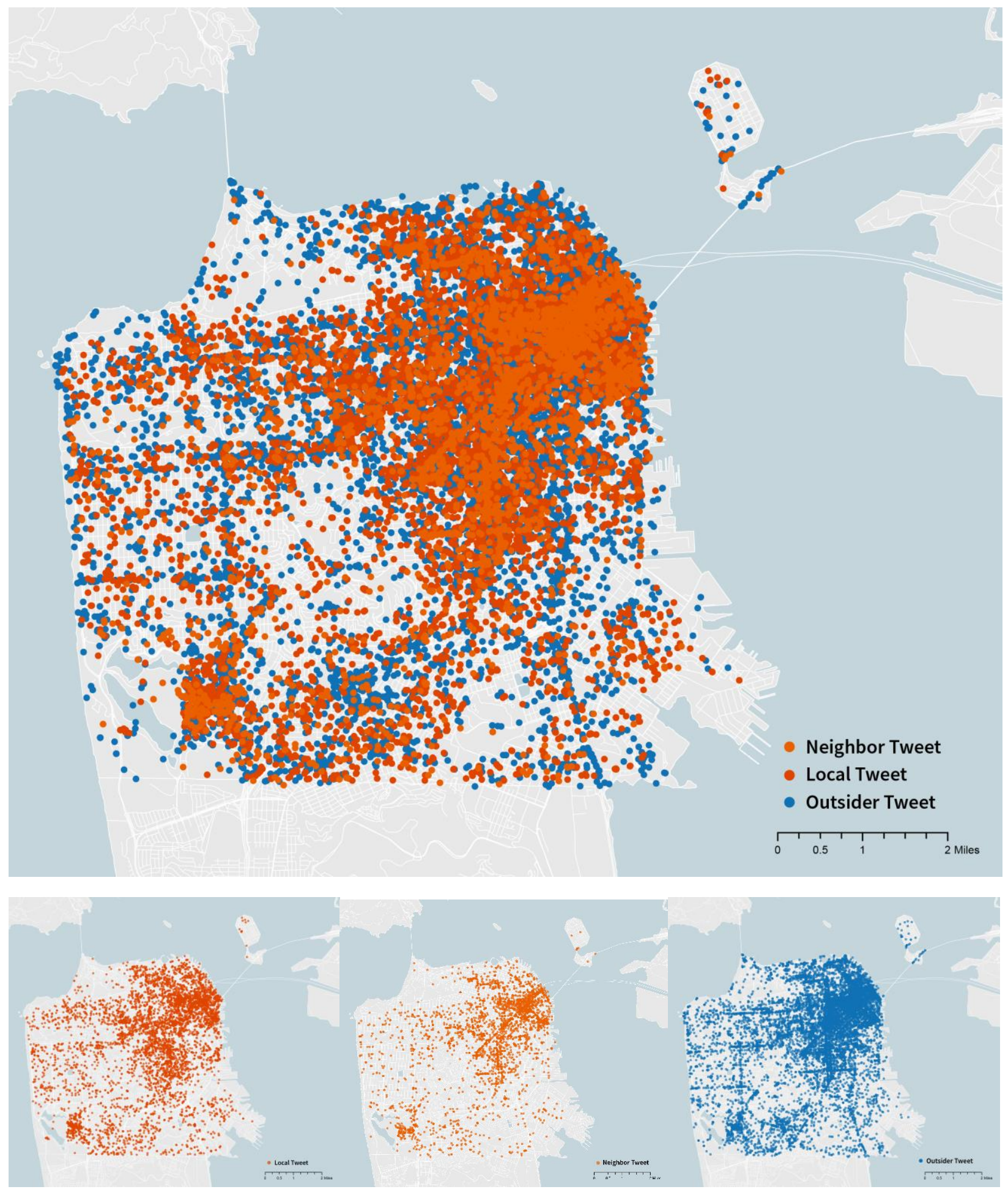
Figure 3. Tracts at risk for gentrification by risk factor and outsider tweets.

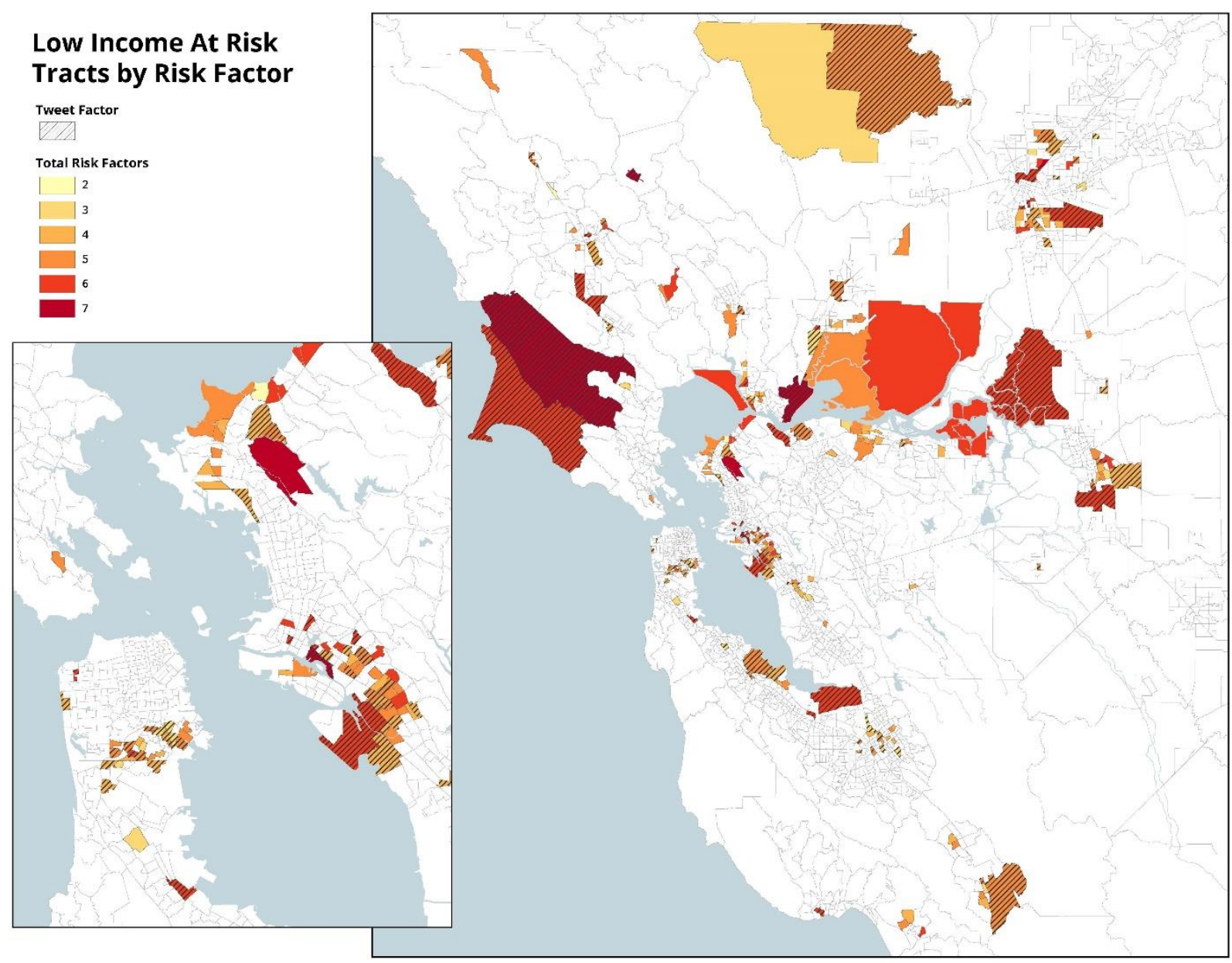


Table 1. Factors predicting ongoing gentrification, 1990-2015.

\begin{tabular}{|c|c|c|c|}
\hline Variable & \multicolumn{2}{|c|}{ Coefficient } & $\begin{array}{l}\text { Odds } \\
\text { ratio }\end{array}$ \\
\hline Household income, 1990 & -0.000 & $* *$ & 1.000 \\
\hline Household income, 1990 , squared & 0.000 & $* * *$ & 1.000 \\
\hline$\%$ households with children, 1990 & -5.566 & $* * *$ & 0.004 \\
\hline \% Latinx residents, 1990 & 1.268 & & 3.554 \\
\hline$\%$ African-American residents, 1990 & 1.149 & & 3.155 \\
\hline$\%$ Asian residents, 1990 & -1.214 & & 0.297 \\
\hline$\%$ college-educated residents, 1990 & -0.262 & & 0.769 \\
\hline$\%$ renters, 1990 & 3.312 & $* * *$ & 27.444 \\
\hline Central city location (dummy) & 0.977 & $* * *$ & 2.656 \\
\hline Transit neighborhood, 1990 (dummy) & 0.032 & & 1.033 \\
\hline Transit neighborhood, 1990-2000 (dummy) & -0.008 & & 0.993 \\
\hline Population density, 1990 & -0.000 & $*$ & 1.000 \\
\hline Employment density, 1990 & -0.000 & $*$ & 1.000 \\
\hline$\%$ of housing units built before 1950 & 3.136 & $* * *$ & 23.005 \\
\hline$\%$ of housing units built $1980-1990$ (recent) & 1.991 & $* *$ & 7.326 \\
\hline$\%$ of residents commuting by car, 1990 & -0.266 & & 0.024 \\
\hline Constant & -0.439 & & 0.645 \\
\hline \multicolumn{4}{|l|}{$<.05,{ }^{\prime *} p<.10$} \\
\hline \multicolumn{4}{|l|}{ stly predicted $77.7 \%$} \\
\hline$=0.342, \chi 2=0.000,-2$ log likelihood $=361.015$ & & & \\
\hline
\end{tabular}


Table 2. Predicting outsider tweets.

\begin{tabular}{|c|c|c|c|c|c|}
\hline Type & Variable & B & Beta & & t-stat \\
\hline Twitter & Total number of tweets, $2012-15$ & 0.000 & .094 & $* * *$ & .001 \\
\hline \multirow{8}{*}{$\begin{array}{c}\text { Socio- } \\
\text { economic } \\
\text { characteristics }\end{array}$} & $\%$ households with children, 2015 & -0.183 & -0.154 & *** & 0.000 \\
\hline & $\%$ of residents aged $25-34,2015$ & 0.088 & 0.043 & & 0.130 \\
\hline & \% Latinx residents, 2015 & -0.023 & -0.027 & & 0.492 \\
\hline & $\%$ African-American residents, 2015 & -0.004 & -0.008 & & 0.745 \\
\hline & $\%$ Asian residents, 2015 & 0.005 & 0.035 & & 0.150 \\
\hline & $\%$ college-educated residents, 2015 & 0.101 & 0.143 & $* * *$ & 3.544 \\
\hline & Central city location (dummy) & 0.024 & 0.074 & $* * *$ & 0.005 \\
\hline & Transit neighborhood (dummy) & 0.034 & 0.105 & $* * *$ & 0.000 \\
\hline \multirow{5}{*}{$\begin{array}{c}\text { Built } \\
\text { environment } \\
\text { characteristics }\end{array}$} & $\%$ of parcels in commercial land use & 0.717 & 0.319 & *** & 0.000 \\
\hline & Employment density, 2014 & -0.000 & -0.079 & $* *$ & 0.009 \\
\hline & Population density, 2015 & -0.000 & -0.183 & $* * *$ & 0.000 \\
\hline & $\%$ of housing units built before 1950 & 0.062 & 0.101 & $* * *$ & 0.001 \\
\hline & $\%$ of housing units built after 2000 & 0.024 & 0.021 & & 0.385 \\
\hline \multirow{10}{*}{$\begin{array}{c}\text { Neighborhood } \\
\text { type }\end{array}$} & Low-income at risk & -0.007 & -0.014 & & 0.572 \\
\hline & Low-income ongoing displacement & 0.029 & 0.036 & & 0.113 \\
\hline & Low-income ongoing gentrification & 0.032 & 0.064 & $* *$ & 0.011 \\
\hline & Advanced gentrification & -0.006 & -0.009 & & 0.715 \\
\hline & Moderate/high-income at risk for exclusion & -0.013 & -0.034 & & 0.238 \\
\hline & Moderate/high-income ongoing exclusion & -0.007 & -0.014 & & 0.591 \\
\hline & Constant & 0.425 & & *** & 19.693 \\
\hline & Adj. $R^{2}$ & 0.282 & & & \\
\hline & Significance & 0.000 & & & \\
\hline & $\mathrm{N}$ & 2,138 & & & \\
\hline \multicolumn{2}{|c|}{${ }^{* * *} p=.000,{ }^{\prime * *} p<.05,{ }^{\prime *} p<.10$} & & & & \\
\hline
\end{tabular}


Table 3. Factors predicting ongoing gentrification 1990-2015, including outsider tweets.

\begin{tabular}{|c|c|c|c|c|}
\hline Type & Variable & Coeffic & icient & $\begin{array}{l}\text { Odds } \\
\text { ratio }\end{array}$ \\
\hline \multirow{8}{*}{$\begin{array}{c}\text { Socio- } \\
\text { economic } \\
\text { characteri } \\
\text { stics }\end{array}$} & Household income, 1990 & $-0.000^{*}$ & $* * *$ & 1.000 \\
\hline & Household income, 1990, squared & $0.000 *$ & $* * *$ & 1.000 \\
\hline & $\%$ households with children, 1990 & $-4.928 *$ & $* *$ & 0.007 \\
\hline & \% Latinx residents, 1990 & 1.749 & & 5.751 \\
\hline & $\%$ African-American residents, 1990 & 1.851 & & 6.366 \\
\hline & $\%$ Asian residents, 1990 & -1.057 & & 0.348 \\
\hline & \% college-educated residents, 1990 & 0.590 & & 1.804 \\
\hline & $\%$ renters, 1990 & $3.209 *$ & $* * *$ & 24.748 \\
\hline \multirow{9}{*}{$\begin{array}{c}\text { Built } \\
\text { environm } \\
\text { ent } \\
\text { characteri } \\
\text { stics }\end{array}$} & Central city location (dummy) & $0.852 *$ & $* *$ & 2.345 \\
\hline & Transit neighborhood, 1990 (dummy) & -0.064 & & 0.938 \\
\hline & Transit neighborhood, 1990-2000 (dummy) & -0.127 & & 0.881 \\
\hline & Population density, 1990 & -0.000 & & 1.000 \\
\hline & Employment density, 1990 & $-0.000 *$ & $*$ & 1.000 \\
\hline & $\%$ of housing units built before 1950 & $3.166 *$ & $* * *$ & 23.719 \\
\hline & $\%$ of housing units built $1980-1990$ (recent) & $1.996 *$ & ** & 7.358 \\
\hline & $\%$ of residents commuting by car, 1990 & 0.631 & & 1.880 \\
\hline & $\%$ of tweets from outsiders & $3.010^{*}$ & $* * *$ & 20.295 \\
\hline & Constant & -3.301 & & 0.370 \\
\hline \multicolumn{5}{|c|}{$* * * p=.000,{ }^{\prime * *} p<.05,{ }^{\prime *} p<.10$} \\
\hline \multicolumn{2}{|c|}{$\mathrm{N}=386, \%$ correctly predicted $79.8 \%$} & & & \\
\hline \multicolumn{4}{|c|}{ Pseudo R-square $=0.364, \chi 2=0.000,-2$ log likelihood $=352.972$} & \\
\hline
\end{tabular}




\section{Table S1}

\section{Gentrification and Displacement Census Tract Typologies}

Regions defined as 9-county Bay Area, and the remaining counties are each their own region.

\begin{tabular}{|c|c|}
\hline Typology & Typology Criteria \\
\hline $\begin{array}{l}\text { Not Losing Low-Income } \\
\text { Households (Low Income) }\end{array}$ & $\begin{array}{ll}\text { - } & \text { Pop in } 2000>500 \\
\text { - } & \text { Low Income Tract in } 2015 \\
\text { - } & \text { Not classified as At Risk of, Ongoing, or Advanced Gentrification }\end{array}$ \\
\hline $\begin{array}{l}\text { At Risk of Gentrification } \\
\text { (Low Income) }\end{array}$ & $\begin{array}{l}\text { - Pop in } 2000>500 \\
\text { - Low Income Tract in } 2015 \\
\text { - Vulnerable in } 2000 \text { (defined below) } \\
\text { - } 4 \text { out of the } 8 \text { of the following is true in 2015: } \\
\text { o Located downtown } \\
\circ \% \text { of units in pre-1950 buildings }>\text { regional median } \\
\circ \text { Share of renter households }>\text { regional median } \\
\circ \text { Share of households with children }<\text { regional median } \\
\circ \text { Share of recent new-build housing }>\text { regional median } \\
\circ \text { Employment density }<\text { regional median } \\
\circ \text { Population density }<\text { regional median } \\
\circ \text { "Hot market" (options defined below table) } \\
\text { - Not currently undergoing displacement or ongoing gentrification }\end{array}$ \\
\hline $\begin{array}{l}\text { Ongoing } \\
\text { Displacement of Low- } \\
\text { Income Households } \\
\text { (Low Income) }\end{array}$ & $\begin{array}{ll}\text { - } & \text { Pop in } 2000>500 \\
\text { - } & \text { Low Income Tract in } 2015 \\
\text { - } & \text { Loss of LI households } 2000-2015 \text { (absolute loss) } \\
\text { - } & \text { LI migration rate in } 2015<\text { in } 2009\end{array}$ \\
\hline $\begin{array}{l}\text { Ongoing Gentrification } \\
\text { (Low Income) }\end{array}$ & $\begin{array}{ll}\text { - } & \text { Low Income Tract in } 2015 \\
\text { - } & \text { Gentrified in 1990-2000 or 2000-2015 (defined below) }\end{array}$ \\
\hline $\begin{array}{l}\text { Advanced Gentrification } \\
\text { (Moderate to High Income }\end{array}$ & $\begin{array}{ll}\text { - } & \text { Pop in } 2000>500 \\
\text { - } & \text { Moderate to High Income Tract in } 2015 \\
\text { - } & \text { Gentrified in in 1990-2000 or 2000-2015 (defined below) }\end{array}$ \\
\hline $\begin{array}{l}\text { Not Losing Low-Income } \\
\text { Households } \\
\text { (Moderate to High Income) }\end{array}$ & $\begin{array}{ll}\text { - } & \text { Pop in } 2000>500 \\
\text { - } & \text { Moderate to High Income Tract in } 2015 \\
\text { - } & \text { Not classified as At Risk of or Ongoing Exclusion }\end{array}$ \\
\hline
\end{tabular}




\begin{tabular}{|c|c|}
\hline $\begin{array}{l}\text { At Risk of Exclusion } \\
\text { (Moderate to High } \\
\text { Income) }\end{array}$ & $\begin{array}{l}\text { Pop in } 2000>500 \\
\text { - Moderate to High Income Tract in } 2015 \\
\text { - } 4 \text { out of the } 7 \text { of the following is true in } 2015: \\
\circ \% \text { of units in prewar buildings }(1950)>\text { regional median } \\
\circ \text { Share of African-American population }<\text { regional median } \\
\circ \text { Share of Latinx population }<\text { regional median } \\
\circ \quad \text { Share of Asian population }<\text { regional median } \\
\circ \text { Share of college-education population }>\text { regional median } \\
\circ \text { Share of car commuters }>\text { regional median } \\
\circ \text { "Hot market" (options defined below table) } \\
\text { Not currently undergoing exclusion }- \text { none of the below classifications are met }\end{array}$ \\
\hline $\begin{array}{l}\text { Displacement of Low- } \\
\text { Income Households - } \\
\text { Ongoing Exclusion } \\
\text { (Moderate to High } \\
\text { Income) }\end{array}$ & $\begin{array}{ll} & \text { Pop in } 2000>500 \\
\text { - } & \text { Moderate to High Income Tract in } 2015 \\
\text { - } & \text { Population stable or growing 2000-2015 } \\
\text { - } & \text { Loss of LI households 2000-2015 (absolute loss) } \\
\text { - } & \text { LI migration rate (percent of all migration to tract that was LI) in } 2015< \\
\text { in } 2009\end{array}$ \\
\hline
\end{tabular}

\section{Definitions of vulnerability, hot market, and gentrification}

- Vulnerable to gentrification in 1990 or 2000

- Housing affordable in base year (housing sales prices or rent $<$ median, depending on whether tract is dominant home-ownership or rental) and (any 2 of 4 )

○ \% low income households $>$ regional median

○ $\%$ college educated $<$ regional median

○ $\%$ renters $>$ regional median

○ $\%$ nonwhite $>$ regional median

- “Hot Market” in 2000 or 2015

$\circ$ Change in median real rent $>$ regional median or

- Change in median value for owner-occupied homes $>$ regional median

- Gentrification from 1990 to 2000 or 2000 to 2015

- Vulnerable in base year (as defined above)

- Demographic change between base and end years:

- Growth in $\%$ college educated $>$ regional median 
- Growth in real median household income (percent change) $>$ regional median

- LI migration rate (percent of all migration to tract that was LI) in $2015<$ in 2009 (only used for 2000-2015 time frame)

○ "Hot market" (defined above)

- If any individual variable is missing, then the whole typology is missing.

- Tracts with a coefficient of variation $>15 \%$ on several key 2015 variables are flagged and determined unreliable:

○ Population

○ Housing units

- Median rent

- Median home value

- Median income

○ College count

○ Renter count 
Table S2. Location quotients of user activity across census tracts.

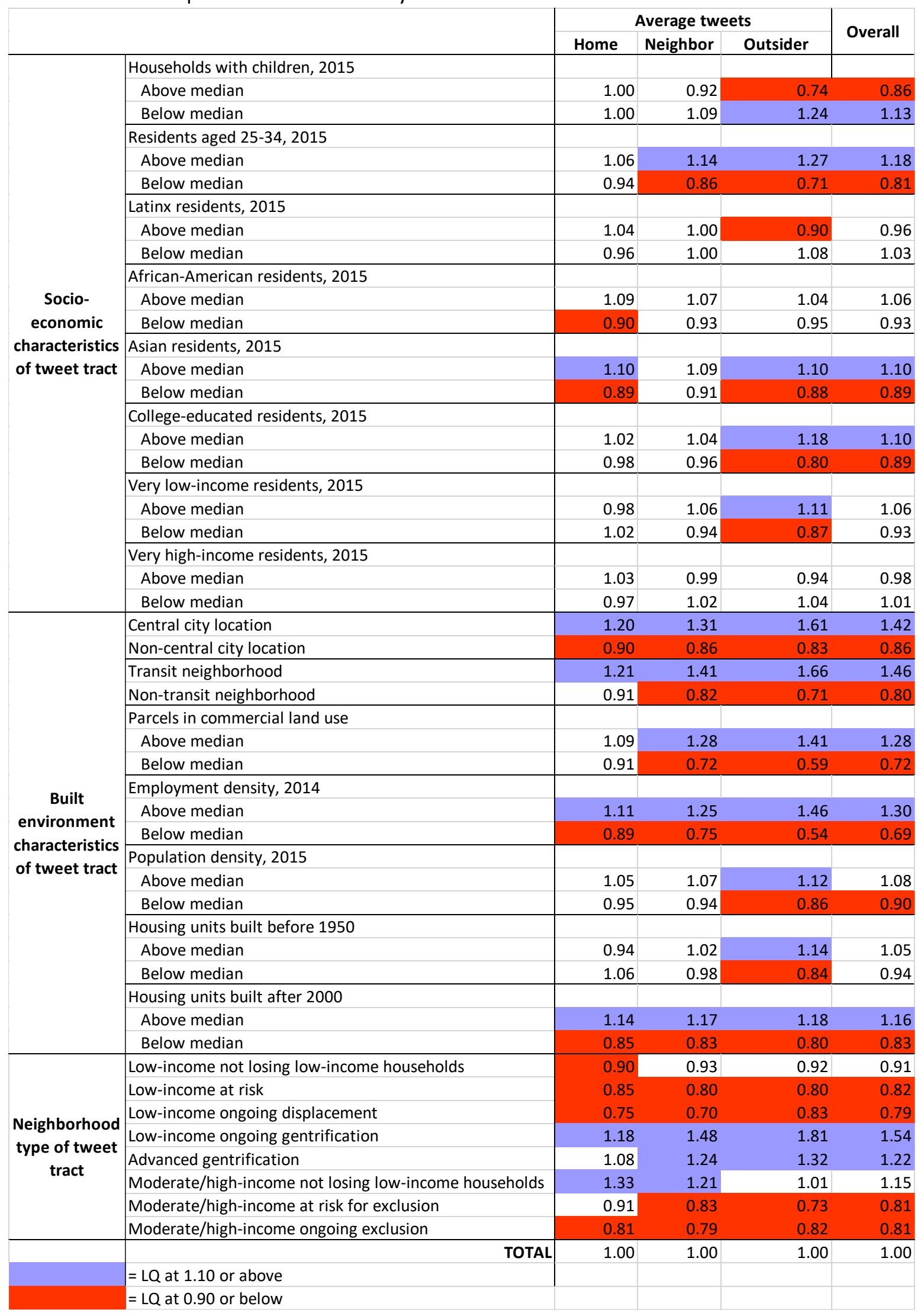


Table S3. Correlation of outsider tweets and conventional risk factors.

\begin{tabular}{lrl} 
Correlation with... & Outsider tweets & \\
\hline Below median share of households with children & 0.176 & $* *$ \\
Above median share of housing units built before 1950 & 0.164 & $* *$ \\
Central city location & 0.165 & $* *$ \\
Above median share renters & $0.133^{* *}$ \\
Above median share housing built in 2000s & -0.025 & \\
Below median residential density & 0.065 & \\
Below median employment density & -0.333 & $* * *$ \\
Hot market 2000-2015 & -0.041 &
\end{tabular}


Table S4. Characteristics of neighborhoods with outsider tweets in at-risk and gentrifying neighborhoods.

\begin{tabular}{|c|c|c|c|c|c|c|c|}
\hline & \multirow[b]{2}{*}{ Variable (mean) } & \multicolumn{3}{|c|}{ Low-Income at Risk } & \multicolumn{3}{|c|}{ Ongoing Gentrification } \\
\hline & & $\begin{array}{l}\text { Below median } \\
\text { outsider tweets }\end{array}$ & $\begin{array}{l}\text { Above medi } \\
\text { outsider twe }\end{array}$ & $\begin{array}{l}\text { dian } \\
\text { eets }\end{array}$ & $\begin{array}{l}\text { Below median } \\
\text { outsider tweets }\end{array}$ & $\begin{array}{l}\text { Above medi } \\
\text { outsider twe }\end{array}$ & $\begin{array}{l}\text { dian } \\
\text { eets }\end{array}$ \\
\hline \multirow{6}{*}{$\begin{array}{c}\text { Socio- } \\
\text { economic } \\
\text { characteristics }\end{array}$} & $\%$ Asian residents, 2015 & 0.510 & $0.651 *$ & $*$ & 0.397 & 0.456 & \\
\hline & $\%$ Latinx residents, 2015 & 0.422 & $0.374 *$ & $*$ & 0.366 & 0.228 & $* * *$ \\
\hline & $\%$ African-American residents, 2015 & 0.461 & $0.338 *$ & $* *$ & 0.325 & 0.251 & \\
\hline & $\%$ college-educated residents, 2015 & 0.182 & $0.209 *$ & $*$ & 0.281 & 0.436 & $* * *$ \\
\hline & $\%$ of residents aged $25-34,2015$ & 0.153 & 0.158 & & 0.181 & 0.221 & $* * *$ \\
\hline & Change in \% low-income, $2000-15$ & 0.170 & 0.222 & & 0.114 & 0.124 & \\
\hline \multirow{5}{*}{$\begin{array}{c}\text { Built } \\
\text { environment } \\
\text { characteristics }\end{array}$} & Central city location & 0.320 & $0.530^{*}$ & $* * *$ & 0.500 & 0.649 & \\
\hline & Transit neighborhood & 0.316 & 0.398 & & 0.302 & 0.634 & $* * *$ \\
\hline & Walkability & 14.84 & $23.55 *$ & $* * *$ & 30.17 & 54.12 & $* * *$ \\
\hline & $\%$ of parcels in commercial land use & 0.034 & $0.072 *$ & $* * *$ & 0.044 & 0.100 & $* * *$ \\
\hline & Population density per sq mile, 2015 & 10155 & 8948 & & 12249 & 17756 & * \\
\hline \multirow{9}{*}{$\begin{array}{c}\text { Twitter user } \\
\text { characteristics }\end{array}$} & $\%$ of outsider tweets from high-income neighborhoods & 0.231 & $0.262 *$ & $* *$ & 0.249 & 0.293 & $* * *$ \\
\hline & $\%$ of outsider tweets from high-educated neighborhoods & 0.351 & $0.454 *$ & $* * *$ & 0.468 & 0.587 & $* * *$ \\
\hline & $\%$ of outsider tweets from African-American neighborhoods & 0.665 & $0.600 *$ & $* *$ & 0.584 & 0.547 & \\
\hline & $\%$ of outsider tweets from Latinx neighborhoods & 0.633 & $0.545 *$ & $* * *$ & 0.537 & $0.434 *$ & $* * *$ \\
\hline & $\%$ of outsider tweets at night & 0.556 & $0.569 *$ & $* *$ & 0.554 & $0.576 *$ & $* *$ \\
\hline & $\%$ of outsider tweets on weekend & 0.337 & 0.330 & & 0.334 & 0.328 & \\
\hline & $\%$ of outsider tweets on weekday & 0.663 & 0.670 & & 0.666 & 0.672 & \\
\hline & $\%$ of outsider tweets from middle-income neighborhoods & 0.343 & 0.349 & & 0.339 & 0.343 & \\
\hline & $\%$ of outsider tweets from low-income neighborhoods & 0.406 & $0.369 *$ & $* *$ & 0.391 & $0.351 *$ & $* *$ \\
\hline \multicolumn{2}{|c|}{${ }^{* * *} p=.000,{ }^{1 * *} p<.05,{ }^{\prime *} p<.10$} & & & & & & \\
\hline
\end{tabular}


Figure S1. Origin of outsider users tweeting in ongoing gentrification tracts versus all other tracts.

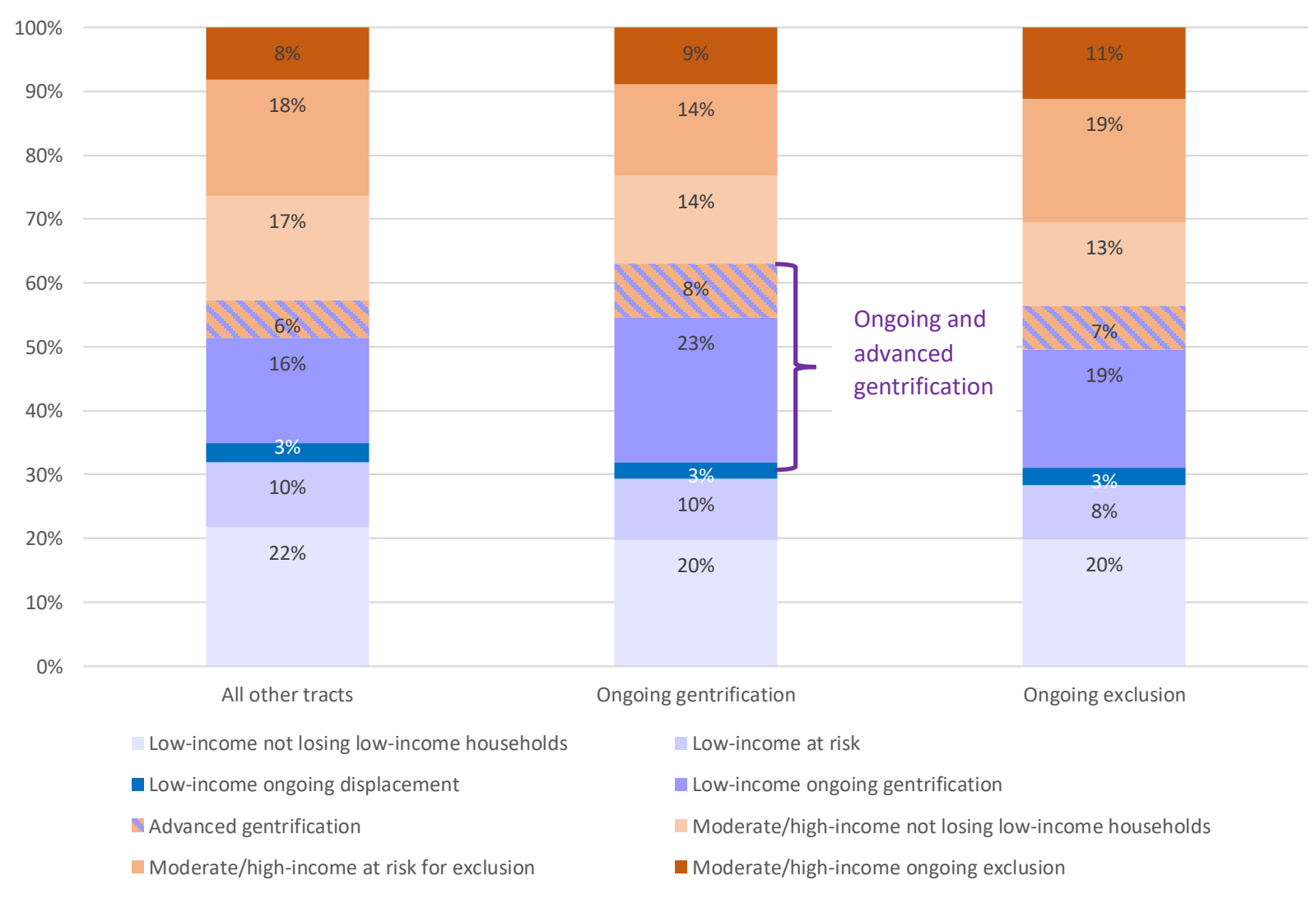


Figure S2. Where outsiders from low-income tracts tracts tweet

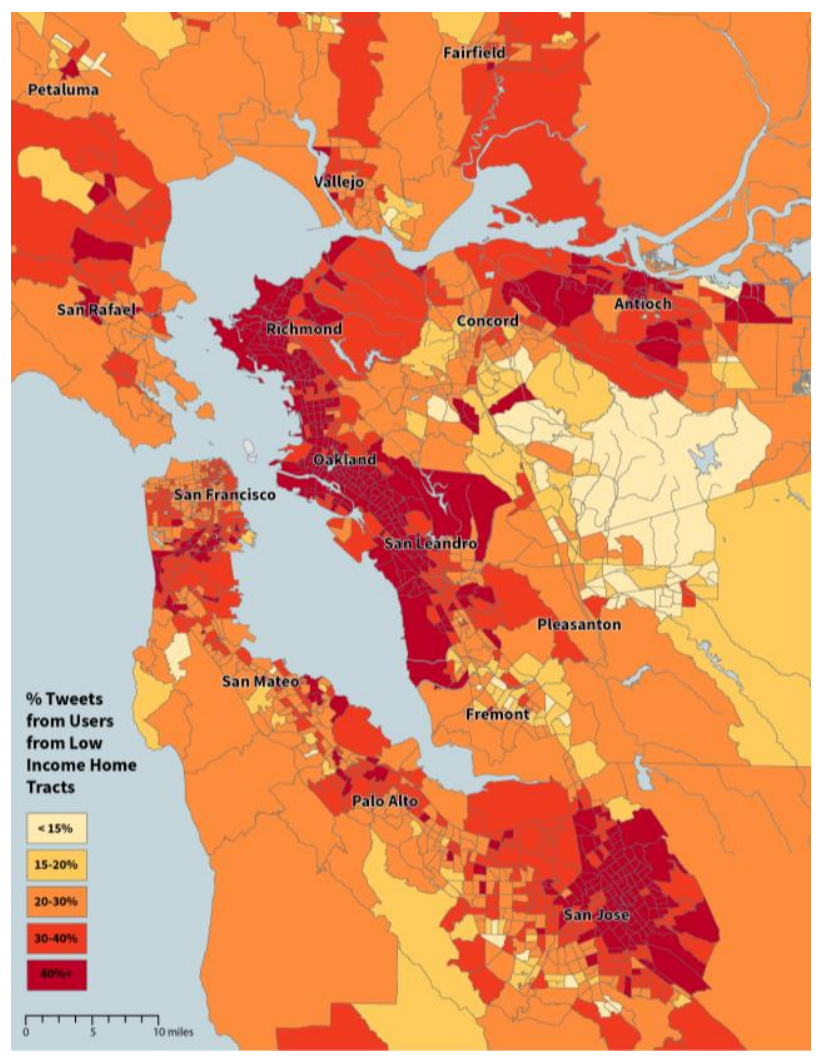

Figure S3. Where outsiders from middle-income

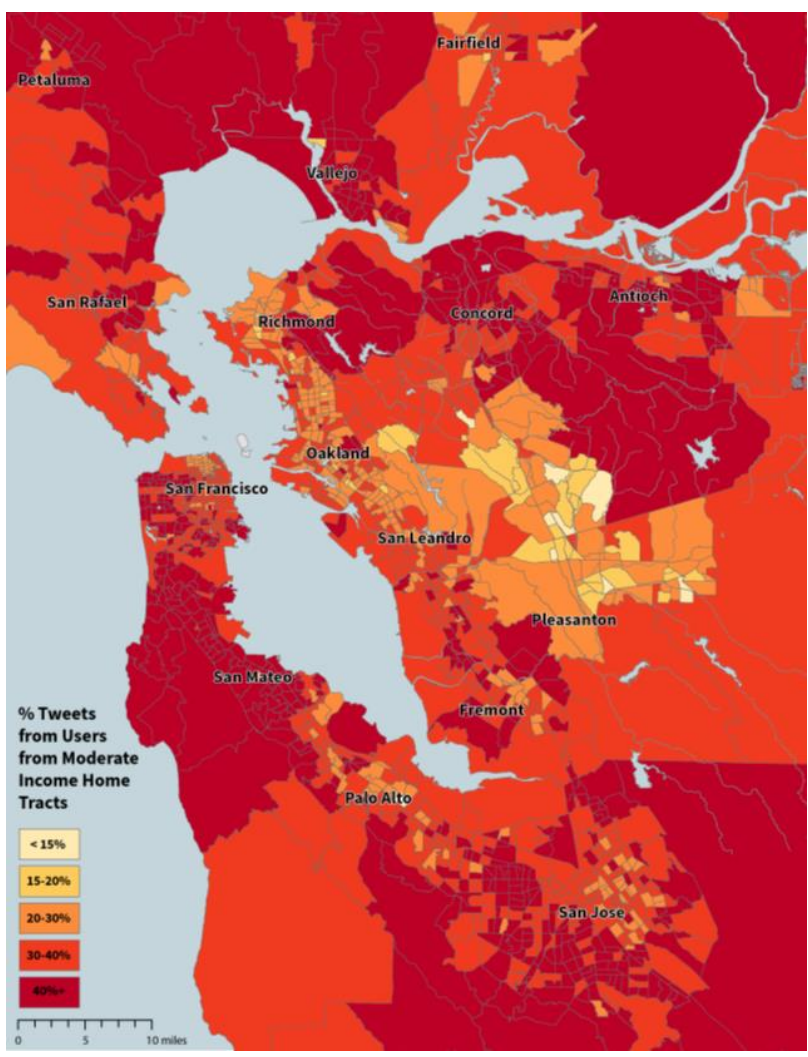


Figure S4. Where outsiders from tracts with above above-median education tweet

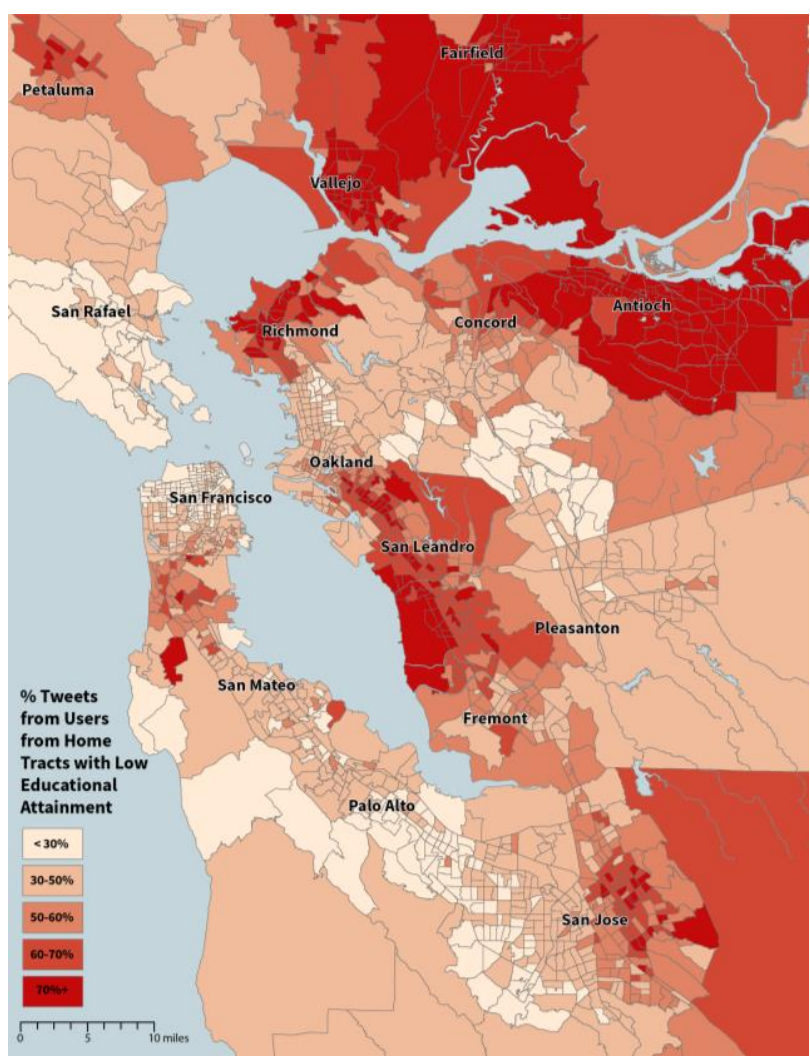

Figure S5. Where outsiders from tracts with below-median education tweet

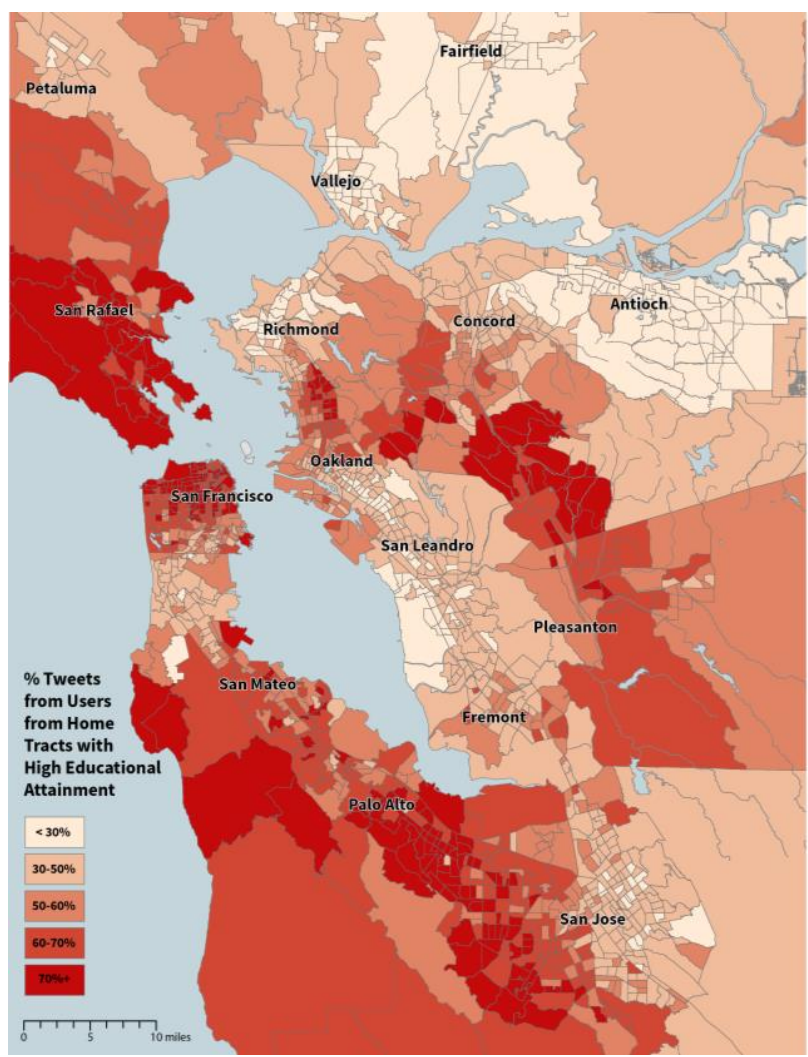


Figure S6. Where outsiders from Non-Hispanic Black tracts tweet

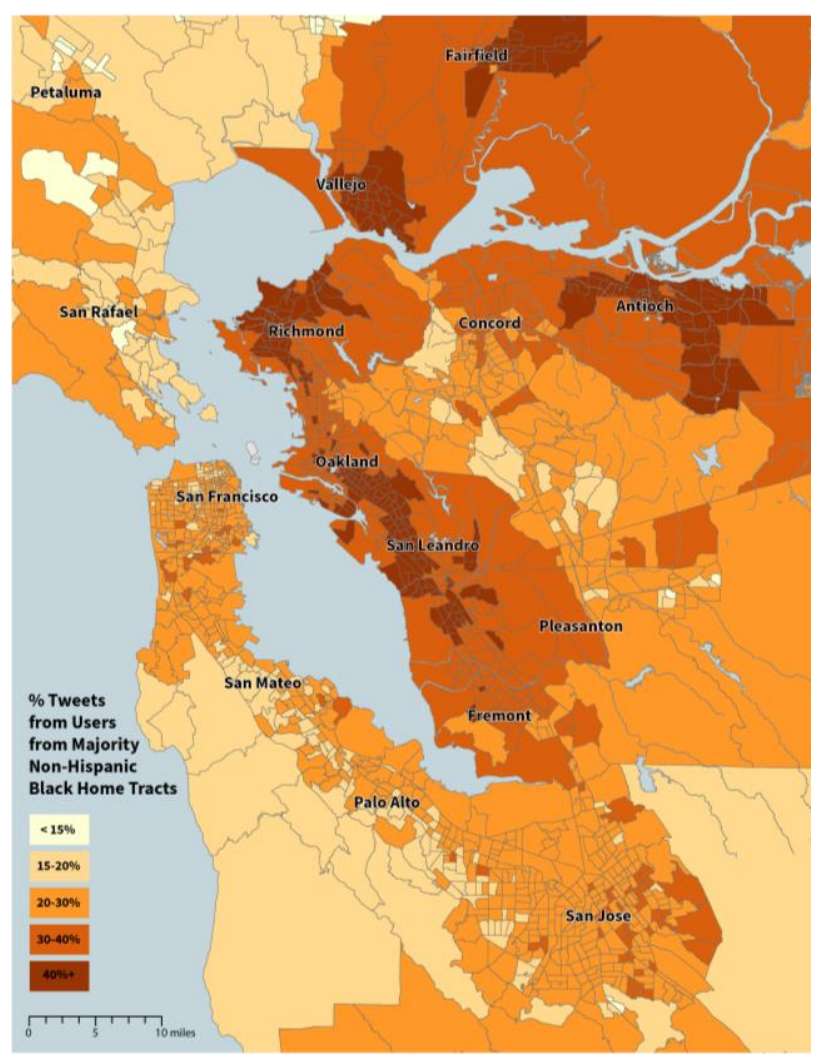

Figure S7. Where outsiders from Latinx tracts tweet

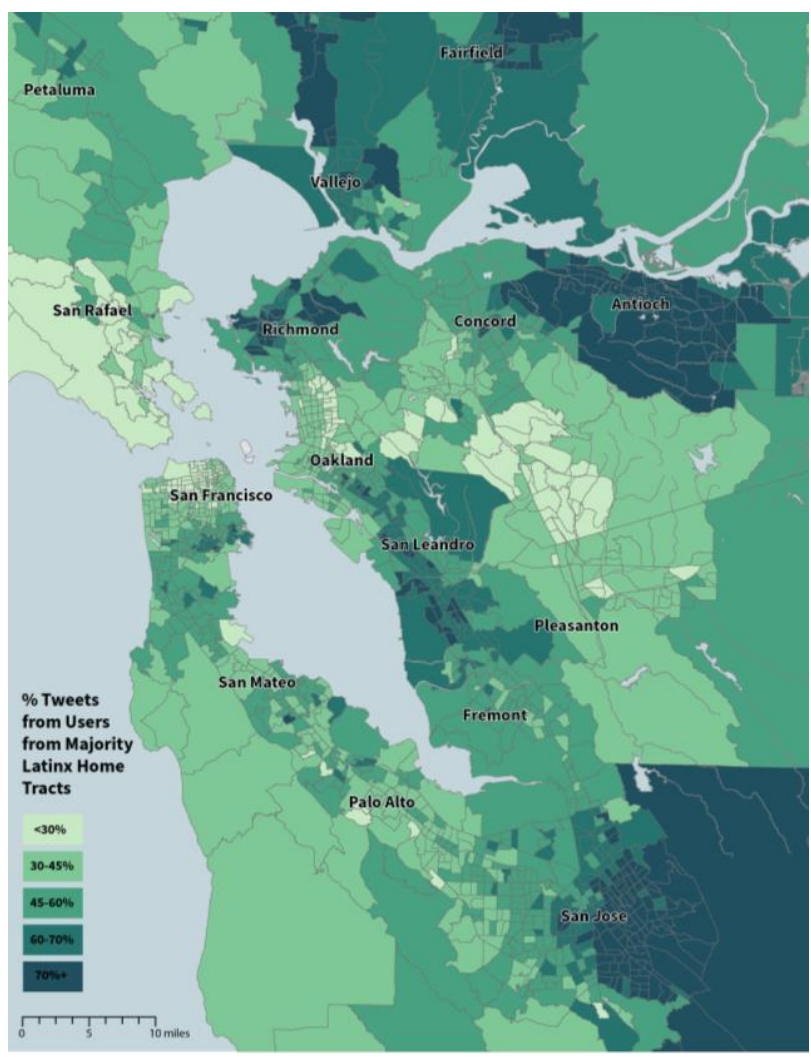


Figure S8. Tweets by local and outsider users by time period. ${ }^{1}$

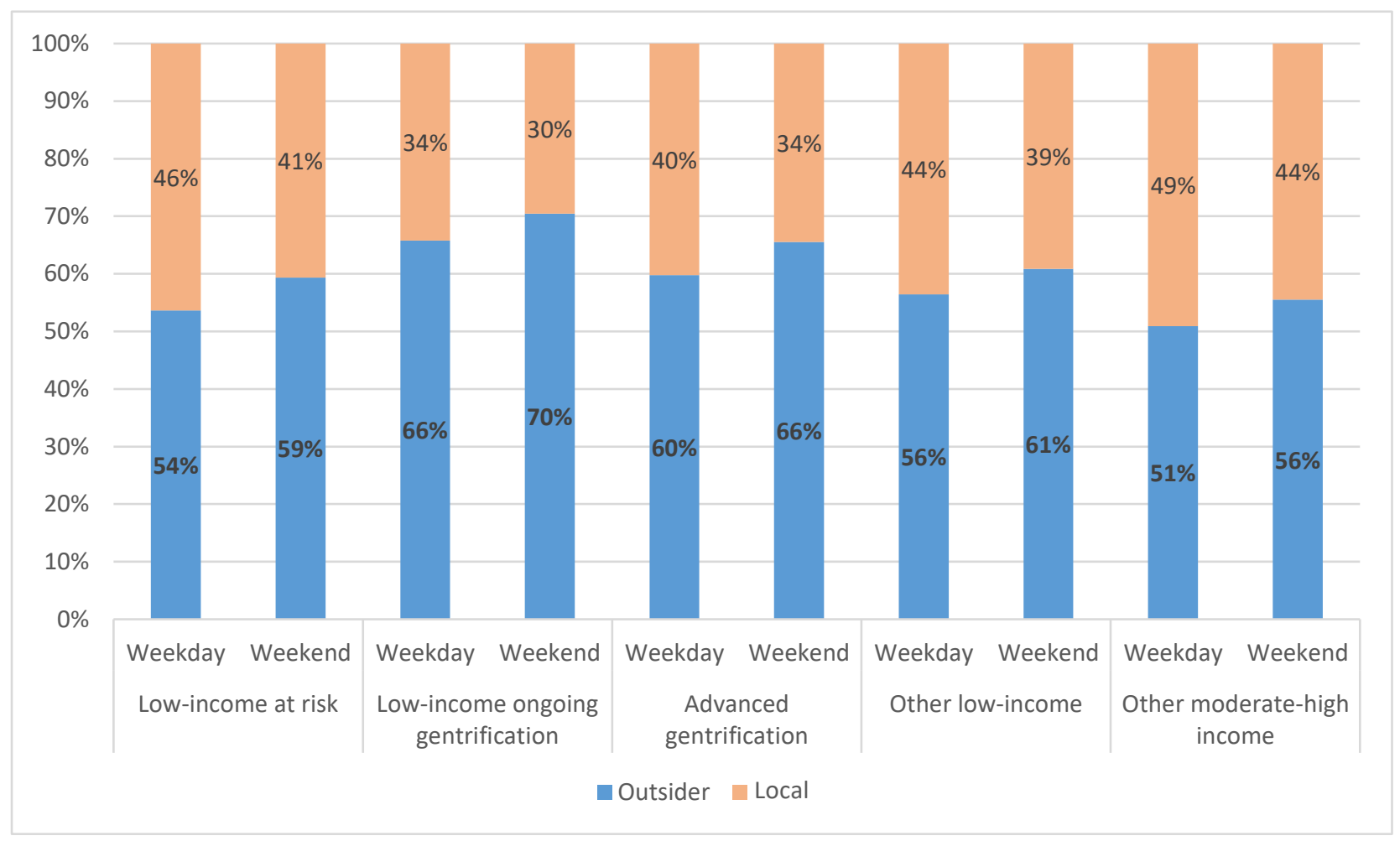

\footnotetext{
${ }^{1}$ Weekdays were defined as Monday-Friday until 18:00 and weekends as 18:00 Friday until 4:00 Monday. Daytime was defined as 4:00-18:00 and nighttime we 18:00-4:00 the next morning.
} 